\title{
Sciendo
}

DOI 10.2478/afepuc-2021-0020

(C) 2021 Author(s). This is an open access article licensed under the Creative Commons Attribution-NonCommercial-NoDerivatives 4.0 International

(https://creativecommons.org/licenses/by-nc-nd/4.0/)

\section{SOCIAL MEDIA FITNESS CHALLENGE - RISKS AND BENEFITS}

\author{
Petr Schlegel, Adam Křehký, Radka Dostálová
}

Department of Physical Education and Sport, Faculty of Education, University of Hradec Králové, Czech Republic

\begin{abstract}
Summary. Social media is part of the lives of young adults. Their influence extends to health behavior or nutrition. "Fitness challenges" often appear and they should affect the motivation to exercise, body composition changes, performance improvement. 67 healthy young adults (32 women, 20.3 years; 35 men, 20.8 years) took part in the "challenge", where they completed 3 series of 12 - 15 push-ups every day for 30 days. After the intervention, both groups showed a statistically significant $(\alpha=0.01)$ improvement, women 5.8 repetitions, men by 7 repetitions. The research was supplemented by a questionnaire, which showed a positive effect on increasing motivation for this activity. Furthermore, it has been shown that "fitness challenges" bring obvious health risks that need to be taken into account. It seems that with the optimal setting of the content of the exercise program, the "fitness challenge" can be a good instrument of increasing the physical acitivty, motivation to exercise, and positively influencing strength performance.
\end{abstract}

Keywords: push-up, exercise, motivation, performance

\section{Introduction}

The use of social media has become an integral part of young people's lives. According to Ilakuvan et al. (2018), $88 \%$ of young adults (18 - 29 years) use them regularly. This virtual space has become, among other things, a source of information, a means of communication, or self-presentation. Over time, groups have been formed within social networks focusing on healthy lifestyles, nutrition, exercise, and appearance (Alberga et al. 2018). These are open groups (e.g. Fitspiration, fitspo, Thinspiration), where users can freely contribute or be just 
passive recipients. These groups have tens of millions of posts and even a higher number of followers (Raggat et al. 2018). The content includes pictures, videos, texts to help with motivation to exercise, and a healthy diet (Tigemann and Zaccardo 2018). Followers ("likers") can thus encounter motivational contributions containing intensive exercise, proper exercise technique, presentation of training or certain methods, or weight reduction.

Part of the "life" of social media are "challenges" that cut across different areas. This phenomenon also applies to exercise groups. Usually, "likers" are encouraged to perform a certain type of exercise that is not demanding on material security, for a relatively short period of up to several weeks. The purpose of the "fitness challenge" is to increase motivation to exercise, achieve visible changes in the body, fun (Polsgrove and Frimming 2013). Similar interventions are rather an exception (Yoshimoto et al. 2016), but still show positive results in the development of physical fitness parameters.

Western society is struggling with an inadequate exercise regime (Choi et al. 2017). By influencing health behavior (Carrotte et al. 2015), modern technologies or social networks could be a way to increase adherence to exercise. Increasing a regular physical activity is an important step in the development of overall health and the fight against civilization diseases.

The aim of this research was to evaluate the effectiveness of the "fitness challenge" and to assess its limitations and threats.

\section{Material and methods}

\section{Participants}

The subjects were students of the University of Hradec Králové; 32 women (20.3 \pm 2.1 years, $161.8 \pm 6.3 \mathrm{~cm}, 62.2 \pm 7.9 \mathrm{~kg}), 35$ men $(20.8 \pm 1.9$ years, $181.9 \pm 6.4 \mathrm{~cm}, 79.7 \pm 7.9 \mathrm{~kg})$. Students were contacted via email and social networks, which described the "fitness challenge" - 30 days of push-ups. Any student could participate, regardless of the field of study, age or sport experience. Prior to registration, the particpants were acquainted in detail with the intention of the research. The participants who missed more than 5 days were excluded from the research.

\section{Measures}

As part of the pre- and posttest, the subjects passed the test of the maximum number of push-ups. Push-up test: Starting position with arms outstretched, palms shoulder-width apart. 
It is important to follow the standard of the push-up with each repetition it visibly touches the chest of the ground, in the upper position the elbows must be straight. Except for the toes, palms, and chest, no other part of the body should touch the ground. The subject can stop the movement at will, but s/he must hold the starting position. The maximum test time is 60 seconds. After completion of the „fitness challenge“ and posttest, the participants filled out a questionnaire, which included questions about social networks, health aspects, subjective feelings of the "challenge", or motivation.

\section{Procedures}

The goal was to perform 3 working series of push-ups each day for 12 - 15 repetitions (pause between sets of 2 minutes), preceded by warm-up and 2 "warm-up" series. Participants were given a stack of different difficulty variants so that everyone could complete the prescribed repetitions. The day before the start, a pretest was performed and the day after the end of the posttest. The "Challenge" was conducted online, each of the participants had to shoot a video according to the required standards and put it in a group on Facebook (FB). Contributions about warming up, exercise techniques, or motivation to exercise were given to this group during the course. It was also possible to submit videos privately. During the research, participants could supplement the push-ups with other physical activities, but they were not allowed to include push-exercises on the upper half of the body. Furthermore, they were not allowed to change their eating habits or exercise regime. The research group was instructed to interrupt the research and contact the organizers in the event of any health problems.

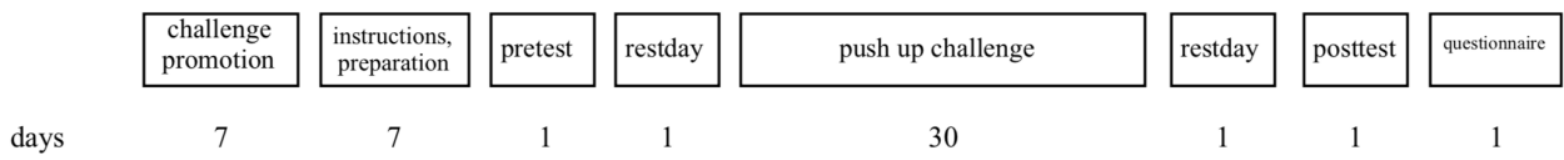

Figure 1

Study time course

\section{Statistical analysis}

The pre- and posttest results were analyzed on a group-by-group basis and also by gender. A parametric t-test was used to evaluate the changes, using the IBM SPSS software, version 20. Furthermore, the Spearman's rank correlation coefficient was applied to verify the relationship of selected quantities. The described software was also used for creating tables and descriptive statistics for the obtained data sample. 


\section{Results}

The results compared the performances of men, women and the whole group. The pretest results show large differences between the sexes (men $24.9 \pm 11.9$, women $4.8 \pm 5.1$ repetitions). The mean value of the whole group was 15.2 repetitions. Both groups showed a statistically significant improvement $(\alpha=0.01)$ (Table 1$)$. In women, the posttest result was $10.5 \pm 6.7$ repetitions, in men $31.9 \pm 10.2$ repetitions. Men improved by more repetitions, but in terms of percentage increase, the shift was more visible in women $(119 \%)$. The whole group also showed statistically significant progress with the value of the posttest 21.7.

Table 1

Pre- and posttest results

\begin{tabular}{|c|c|c|c|c|c|c|}
\hline & $\mathbf{N}$ & pre & post & difference & \% & t \\
\hline Women & 32 & 4.8 & 10.5 & 5.8 & 119 & -9.133 \\
\hline Men & 35 & 24.9 & 31.9 & 7 & 28 & -8.505 \\
\hline All & 67 & 15.3 & 21.7 & 6.4 & 42 & -12.177 \\
\hline
\end{tabular}

pre - pretest average; post - posttest average; \%- proventual diffence; $t$ - $t$ value $(p<0,01)$

Within the statistical data processing, the correlation of selected quantities was performed. The relationship between the values, height and weight was investigated. Due to significant differences between men and women, they were compared separately (Tables 2 and 3). A weak correlation was found between the variables in both groups (maximum -0.279). It can be stated that neither height nor weight were significantly related to the results of pre- and posttest in men and women.

Table 2

Correlation of height, weight and test results in women

\begin{tabular}{|c|c|c|c|c|c|c|}
\hline & average & SD & pretest & posttest & height & weight \\
\hline pretest & 4.75 & 5.10 & 1 & $\mathbf{0 . 8 5 1}$ & -0.202 & -0.122 \\
\hline posttest & 10.53 & 6.72 & $\mathbf{0 . 8 5 1}$ & 1 & -0.269 & -0.180 \\
\hline height & 168.13 & 6.27 & -0.202 & -0.269 & 1 & $\mathbf{0 . 5 7 8}$ \\
\hline weight & 62.16 & 7.90 & -0.122 & -0.180 & $\mathbf{0 . 5 7 8}$ & 1 \\
\hline
\end{tabular}

Table 3

Correlation of height, weight and test results in men

\begin{tabular}{|c|c|c|c|c|c|c|}
\hline & average & SD & pretest & posttest & height & weight \\
\hline pretest & 24.86 & 11.92 & 1 & $\mathbf{0 . 9 1 4}$ & -0.213 & -0.207 \\
\hline posttest & 31.86 & 10.25 & $\mathbf{0 . 9 1 4}$ & 1 & -0.279 & -0.236 \\
\hline height & 79.69 & 7.93 & -0.213 & -0.279 & 1 & $\mathbf{0 . 4 8 9}$ \\
\hline weight & 181.89 & 6.42 & -0.207 & -0.236 & $\mathbf{0 . 4 8 9}$ & 1 \\
\hline
\end{tabular}


The selected results of the questionnaire show (Table 4) that almost all (95\%) use social networks on a daily basis. Facebook (95\%) and Instagram (92 \%) have a dominant representation. Most respondents have already encountered a "fitness challenge" and more than half $(52 \%)$ have actively participated in it. During the "challenge", $20 \%$ developed certain health problems (pain), which led to the omission of exercise. Nevertheless, $30 \%$ of participants exercised every day and $34 \%$ missed 3 or 4 days. In five participants $(7.5 \%)$, the consequences remained in the form of certain pain, which concerned the shoulder and wrist area. It is important to mention that overall the "challenge" was perceived positively $(7.9 / 10)$ and the majority of participants would be involved in another similar activity ( $82 \%)$.

Table 4

Questionnaire results

\begin{tabular}{|ll|}
\hline How often do you follow social networks? & $95 \%$ daily \\
What social networks do you use? & $95 \%$ facebook, $92 \%$ instagram \\
Have you participated a similar "fitness challenge"? & $82 \%$ yes \\
Have you participated in such a "challenge" before? & $52 \%$ yes \\
Have you posted posts about your workout on social & \\
networks more often? & $19 \%$ yes \\
& $0 \times 30 \%, 1 \times 25 \%, 2 \times 26 \%, 3 x 20 \%$, \\
How often have you missed an exercise? & 4 x 14 \% \\
Did health problems (pain) occur during the course that led & $20 \%$ yes \\
to the omission of exercise? & $8,3 \%$ yes (shoulder, wrist) \\
Are there any pains left after (caused by "challenge")? & $7.9 / 10$ (10 - absolutely positive) \\
How do you perceive the "fitness challenge"? & $82 \%$ yes \\
Would you join the next "challenge"? & \\
\hline
\end{tabular}

\section{Discussion}

Young adults very often use social networks (Ilakuvan et al. 2018), which was confirmed in this research. $95 \%$ of respondents use them daily and are mainly on Facebook and Instagram. This finding has consequences in the form of a strong influence of social media on humans. The frequent exploitation of social media can be used to disseminate information and positively influence the target group (Berg et al. 2020). Facebook (closed group) has in this research proven to be a suitable tool. The content was carefully chosen to educate and also motivate. The nature of the contributions is an important factor that can influence the approach 
to the exercise or body image (Tiggemann \& Zaccardo 2015). This aspect must be respected because the content of groups of the type "fitspiration" is often focused on appearance (displaying edited photos, presentation of unreal beauty), which can negatively affect followers/likers (Tiggemann \& Zaccardo, 2018).

The existence of "fitness challenges" is not unusual and was met by $82 \%$ of participants. Even more than half (52\%) have actively participated in it in the past. This is an activity that deserves attention and it is important to know its strengths and weaknesses. It is confirmed that young adults are confronted with groups, pictures, or texts, which have the potential to influence a healthy lifestyle, exercise, and nutrition (Williams et al. 2014). In this context, it is important to note that the content and quality of a message may vary and is perceived accordingly by the user (Raggatt et al. 2018).

The chosen intervention is non-traditional and represents a high-frequency one-sided program. The usual length is at least $6-8$ weeks (Schoenfeld et al. 2017). A similar design can be found in Takai et al. (2013) and Yoshimoto et al. (2016), where participants completed 100 squats each day for 45 days. Both studies have proven to be positive in the development of strength performance and body composition. In the case of push-ups, no comparable research was found. However, the inclusion of push-ups twice a week for 8 weeks has been shown to develop upper body strength (Chulvi-Medrano et al. 2012). In the case of this "challenge", 90 work series were completed during the whole period, which represents a significantly higher volume than is usually applied (Lima et al. 2018). Due to the number and size of muscle groups involved, there is a lower potential to change body composition. In order to achieve measurable changes (fat, lean body mass), it would be appropriate to supplement such program with other exercises and adapt the exercise method (Myers et al. 2015).

Participants achieved a statistically significant $(\alpha=0.01)$ improvement, as well as a separate group of women and men. The reason for the improvement may be the relatively high volume of exercise. Another possible factor may be the exercise of the push-up, which may not have been a regular part of their physical activity, which brings the potential for a complete adaptation in the form of inter and intramuscular coordination. Due to the short duration of the intervention, no muscle hypertrophy could occur that would affect the results (Schoenfeld et al. 2017). In particular, women recorded significant progress in the absolute number of push ups, the number more than doubled. Performance in men can be described as above average, women showed values that indicate a lower level of strength of the upper half of the body. These are the expected outcomes (Paoli \& Bianco 2015). 
For bodyweight strength performances (pull-up, push-up), weight is essential, which is directly proportional to the number of repetitions performed (Lima et al. 2018). However, the correlation did not confirm this fact (Table 4). For the sample, the weight had no statistically significant relationship with the number of push-ups before or after the intervention. According to the average weight (females $62.2 \mathrm{~kg}$, males $79.7 \mathrm{~kg}$ ), it was a group without major deviations from the standard (overweight, obesity), otherwise they would probably show the opposite tendency (Sword 2012).

The push-up is one of the basic exercises for developing upper body strength (Calatayud et al. 2014). When placed alone without further exercise, an asymmetric load is created that is not optimal for the shoulder joint, spine, or posture (Dhahbi et al. 2018). The content of the intervention was set to correspond to the real situation on social networks. A proper exercise program must include exercises that affect all the large joints, spine and will strenghten large muscle groups. It should also include activities that develop the function of the cardiovascular system. Only in this way a harmonious development of fitness can be achieved (Paoli \& Bianko 2015).

The questionnaire showed that only $30 \%$ of participants had not missed a single exercise, $34 \%$ had missed three or four times. It turns out that maintaining motivation to exercise on a daily basis is difficult. At the same time, it is related to the information that $20 \%$ of the sample experienced increased discomfort in the form of some pain, which was then a reason to skip the exercise session. For the sporting population, such a condition is often received positively, but may also have the opposite effect (Duncan et al. 2010).

The unsupervised exercise that has been the subject of this research carries certain risks. Although participants receive instructions on exercise techniques, or warm-up, they are not under professional supervision. The technique has a clear effect on muscle activation, joint loading and overall health effect. In the case of the push-up, it is mainly the area of the shoulder blade, shoulder and wrist (Dhahbi et al. 2018). In five participants, the health problems persisted even after the end of the "challenge" and the problem was in the mentioned parts of the body. This could be due to technical deficiencies, excessive loads or previous injuries (Goossens et al. 2019). A related problem in these "challenges" is the absence of musculoskeletal diagnostics, which would determine the organism's readiness for such a program (Toivo et al. 2018). Participants must assess their own health, which can be risky.

Overall, the "challenge" was perceived positively (7.9 points out of 10), despite the problems in the form of discomfort/pain during the exercise. The assessment may be affected by performance improvements (Duncan et al. 2010), which may have been surprising to many. 
Although the participants had to practice on their own, they were part of a group that helped them. In this context, a stable contact via Facebook in the form of regular posts was also important. The "Challenge" had a positive motivational impact, $82 \%$ of participants would again engage in a similar activity.

The exercises were checked only in the pre- and posttest, the participants were not supervised during the intervention. It is therefore not possible to assess with certainty to what extent the numbers of series or repetitions were observed. However, it was a research plan to create real conditions for the "fitness challenge". During the research, the weight of some participants may also have changed, which may have affected the test result (Chulvi-Medrano et al. 2012). Although participants were encouraged to follow their current eating habits and exercise regimen, this fact cannot be excluded. The video performance evaluation is not standard, however, but it is similarly used in other sports (Serafini et al. 2018).

\section{Conclusion}

Social networks are a space where groups have formed to spread information about exercise, nutrition and a healthy lifestyle. One means is the "fitness challenge", which aims to increase motivation to exercise, help reduce weight or improve performance. In the research, the "challenge" focused on push-ups proved to be a good means of developing the strength abilities of the upper body. In the case of optimally chosen content, a "fitness challenge" can be a good source of motivation, information, improved strength performance or a positive effect on body image in young adults. At the same time, it can help increase the amount of physical activity that is generally insufficient in Western society. It is important to take into account the health risks and deficiencies associated with exercise without professional supervision. 


\section{References}

1. AlBERGA, A. S., S. J. WITHNELL \& K. M. von RANSON, 2018. Fitspiration and thinspiration: A comparison across three social networking sites. In: Journal of Eating Disorders. 6(1), 39.

2. BERG, S., J. FOREST \& F. STENSENG, 2020. When Passion Does Not Change, but Emotions Do: Testing a Social Media Intervention Related to Exercise Activity Engagement. In: Frontiers in Psychology. 11, 71.

3. CALATAYUD, J., S. BORREANI, J. C. COLADO, F. MARTIN \& M. E. ROGERS, 2014. Muscle activity levels in upper-body push exercises with different loads and stability conditions. In: The Physician and Sportsmedicine. 42(4), 106-119.

4. CARROTTE, E. R., I. PRICHARD \& M. S. C. LIM, 2017. "Fitspiration" on Social Media: A Content Analysis of Gendered Images. In: Journal of Medical Internet Research. 19(3).

5. DHAhBI, W., H. ChAABEne, A. CHAOUACHI, J. PADUlO, D. G BEHM, J. COCHRANE \& K. CHAMARI, 2018. Kinetic analysis of push-up exercises: A systematic review with practical recommendations. In: Sports Biomechanics. 1-40.

6. DUNCAN, L. R., C. R. HALL, P. M. WILSON \& O. JENNY, 2010. Exercise motivation: A cross-sectional analysis examining its relationships with frequency, intensity, and duration of exercise. In: International Journal of Behavioral Nutrition and Physical Activity. 7(1), 7.

7. GOOSSENS, L., R. DE RIDDER, G. CARDON, E. WITVROUW, R. VERRELST \& D. DE CLERCQ, 2019. Injury prevention in physical education teacher education students: Lessons from sports. A systematic review. In: European Physical Education Review. 25(1), 156-173.

8. CHOI, J., M. LEE, J. LEE, D. KANG \& J.-Y. CHOI, 2017. Correlates associated with participation in physical activity among adults: A systematic review of reviews and update. In: BMC Public Health. 17(1), 356.

9. CHULVI - MEDRANO, I., E. MARTÍNEZ-BALLESTER \& L. MASIÁ-TORTOSA, 2012. Comparison of the Effects of an Eight-Week Push-Up Program Using Stable Versus Unstable Surfaces. In: International Journal of Sports Physical Therapy. 7(6), 586-594.

10. ILAKKUVAN, V., A. JOHNSON, A. C. VILLANTI, W. D. EVANS \& M. TURNER, 2019. Patterns of Social Media Use and Their Relationship to Health Risks Among Young Adults. In: Journal of Adolescent Health. 64(2), 158-164. 
11. LIMA, C., LI, Y., LOW, J. L., HERAT, N., \& D. G. BEHM, 2018. Superior TrainingSpecific Adaptations With an 8-Week Yoak Push-up Training Program. In: Journal of Strength and Conditioning Research, 32(9), 2409-2418.

12. MYERS, T. R., M. G. SCHNEIDER, M. S. SCHMALE \& T. J. HAZELL, 2015. Wholebody aerobic resistance training circuit improves aerobic fitness and muscle strength in sedentary young females. In: Journal of Strength and Conditioning Research. 29(6), 1592 1600.

13. PAOLI, A., \& A. BIANCO, 2015. What Is Fitness Training? Definitions and Implications: A Systematic Review Article. In: Iranian Journal of Public Health. 44(5), 602-614.

14. POLSGROVE, M. J. \& R. E. FRIMMING, 2013. A Creative Way to Utilize Social Media to Enhance Fitness and Health Knowledge. In: Strategies. 26(2), 3-7.

15. RAGGATT, M., C. J. C. WRIGHT, E. CARROTTE, R. JENKINSON, K. MULGREW, I. PRICHARD \& M. S. C. LIM, 2018. "I aspire to look and feel healthy like the posts convey": Engagement with fitness inspiration on social media and perceptions of its influence on health and wellbeing. In: BMC Public Health. 18(1), 1002.

16. SERAFINI, P. R., Y. FEITO \& G. T. MANGINE, 2018. Self-reported Measures of Strength and Sport-Specific Skills Distinguish Ranking in an International Online Fitness Competition. In: Journal of Strength and Conditioning Research. 32(12), 3474-3484.

17. SCHOENFELD, B. J., J. GRGIC, D. OGBORN \& J. W. KRIEGER, 2017. Strength and Hypertrophy Adaptations Between Low- vs. High-Load Resistance Training: A Systematic Review and Meta-analysis. In: Journal of Strength and Conditioning Research. 31(12), $3508-3523$.

18. SWORD, D. O., 2012. Exercise as a Management Strategy for the Overweight and Obese: Where Does Resistance Exercise Fit in? In: Strength \& Conditioning Journal, 34(5), 4755.

19. TAKAI, Y., Y. FUKUNAGA, E. FUJITA, H. MORI, T. YOSHIMOTO, M. YAMAMOTO \& H. KANEHISA, 2013. Effects of Body Mass-Based Squat Training in Adolescent Boys. In: Journal of Sports Science \& Medicine. 12(1), 60-65.

20. TIGGEMANN, M., \& M. ZACCARDO, 2015. "Exercise to be fit, not skinny": The effect of fitspiration imagery on women's body image. In: Body Image, 15, 61-67.

21. TIGGEMANN, M. \& M. ZACCARDO, 2018. 'Strong is the new skinny': A content analysis of \#fitspiration images on Instagram. In: Journal of Health Psychology. 23(8), 1003-1011. 
22. TOIVO, K., P. KANNUS, S. KOKKO, L. ALANKO, O. J. HEINONEN, R. KORPELAINEN \& J. PARKKARI, 2018. Musculoskeletal examination in young athletes and non-athletes: The Finnish Health Promoting Sports Club (FHPSC) study. In: BMJ Open Sport \& Exercise Medicine. 4(1), e000376.

23. WILLIAMS, G., M. P. HAMM, J. SHULHAN, B. VANDERMEER \& L. HARTLING, 2014. Social media interventions for diet and exercise behaviours: A systematic review and meta-analysis of randomised controlled trials. In: BMJ Open. 4(2), e003926.

24. YOSHIMOTO, T., Y. TAKAI, Y. FUKUNAGA, E. FUJITA, M. YAMAMOTO \& H. KANEHISA, 2016. In: Effects of school-based squat training in adolescent girls. In: The Journal of Sports Medicine and Physical Fitness. 56(6), 678-683. 